\title{
บUsisersily
}

\section{A qualitative exploration of patient and healthcare professionals' views and experiences of palliative rehabilitation during advanced lung cancer treatment}

Payne, C., Mcllfatrick, S. J., Larkin, P. J., Dunwoody, L., \& Gracey, J. (2018). A qualitative exploration of patient and healthcare professionals' views and experiences of palliative rehabilitation during advanced lung cancer treatment. Palliative Medicine, 32(10), 1624-1632. https://doi.org/10.1177/0269216318794086

Link to publication record in Ulster University Research Portal

Published in:

Palliative Medicine

Publication Status:

Published (in print/issue): 01/12/2018

DOI:

10.1177/0269216318794086

Document Version

Author Accepted version

\section{General rights}

Copyright for the publications made accessible via Ulster University's Research Portal is retained by the author(s) and / or other copyright owners and it is a condition of accessing these publications that users recognise and abide by the legal requirements associated with these rights.

\section{Take down policy}

The Research Portal is Ulster University's institutional repository that provides access to Ulster's research outputs. Every effort has been made to ensure that content in the Research Portal does not infringe any person's rights, or applicable UK laws. If you discover content in the Research Portal that you believe breaches copyright or violates any law, please contact pure-support@ulster.ac.uk. 
TITLE: A qualitative exploration of patient and healthcare professionals' views and experiences of palliative rehabilitation during advanced lung cancer treatment.

\section{SHORT TITLE: Perspectives on palliative rehabilitation}

\section{Word Count: Excluding quotations, references and tables 3000 words [Max 3000]}

\section{Author details}

Dr. Cathy Payne, Research Associate, Institute of Nursing and Health Research, Ulster University, Northern Ireland

Professor Sonja Mcllfatrick, Head of School, School of Nursing, Institute of Nursing and Health Research, Ulster University, Northern Ireland Professor Philip Larkin, Professor of Clinical Nursing (Palliative Care), School of Nursing, Midwifery and Health Systems, Health Sciences Centre, University College Dublin and Our Lady's Hospice and Care Services, Dublin, Republic of Ireland.

Dr Lynn Dunwoody, Lecturer, Psychology Research Institute, University of Ulster, Northern Ireland.

Dr Jackie Gracey, Lecturer, Institute of Nursing and Health Research, School of Health Sciences, Ulster University, Northern Ireland

\section{Correspondence author:}

Dr. Cathy Payne, Research Associate, Institute of Nursing and Health Research, Ulster University, Northern Ireland, Newtownabbey, Belfast BT37 0QB. Email: c.payne@ulster.ac.uk 


\section{ABSTRACT}

Background Limited evidence exists on the impact of palliative rehabilitation during systemic treatment of advanced cancer.

Aim To explore the experiences and perceptions of patients and healthcare professionals on the feasibility and acceptability of palliative rehabilitation during advanced lung cancer treatment.

Design Qualitative design using individual semi-structured interviews, transcribed verbatim and analysed thematically.

Setting/participants Eight patients and six healthcare professionals were recruited from a regional cancer centre in the UK following completion of a six-week individualised behaviour change study which combined physical activity and nutritional guidance.

Results Palliative rehabilitation and study participation were positively viewed by both participants and healthcare professionals. Five themes were identified from patient interviews within an overarching theme of Living with and beyond an advanced cancer diagnosis (1) Challenges of living with incurable cancer (2) Personal and altruistic reasons for participating in rehabilitation (3) Applicability of palliative rehabilitation content (4) Barriers and facilitators to adherence (5) Positive impact on self and others. Three themes were identified from healthcare professionals, within an overarching theme of Palliative Rehabilitation: Exploring the concept (1) Pre-study mixed perceptions of palliative rehabilitation (2) Perceived benefits for patients and families (3) Lessons for future research.

Conclusions Patients described personal benefits associated with setting their own goals for physical activity and dietary intake. Healthcare professionals who initially expressed a negative or indifferent stance towards palliative rehabilitation, displayed a mind-set change and were keen to explore further opportunities to expand the evidence base.

KEYWORDS: Rehabilitation, Lung Neoplasms, Exercise, Diet Therapy, Palliative Care 


\section{KEY STATEMENTS (1-3 bullets for each)}

\section{What is already known about the topic?}

- The optimal timing, composition and inclusion criteria for palliative rehabilitation interventions is unclear.

- Limited information also exists regarding patient's own preferences for undertaking individualised palliative rehabilitation.

- Clinician views of palliative rehabilitation are inconsistent leading to rehabilitative services being underutilised.

\section{What this paper adds}

- Patient participants perceived that an individualised behaviour change programme which combined physical activity, exercise and nutritional guidance was of value and should be offered to all those wishing to be actively involved in their cancer management.

- Engagement in a palliative rehabilitation study led healthcare professionals to have more positive attitudes towards rehabilitation as a component of advanced cancer treatment.

\section{Implications for practice, theory or policy}

- This study highlights the potential impact of palliative rehabilitation as a component of advanced cancer management but further work is need to incorporate rehabilitation within lung cancer treatment pathways.

- Further research is needed to determine if the views held by patient participants are reflective of the wider population of those receiving systemic therapy with palliative intent. 


\section{BACKGROUND}

Lung cancer is the leading cause of cancer deaths across the world [1], with non-small cell lung cancer (NSCLC) accounting for approximately 70 to $80 \%$ of all western lung cancer diagnoses [2]. As this population have a high symptom burden arising from both the cancer and its treatment [3], interest has grown internationally regarding the potential benefits of providing rehabilitation to support functional wellbeing and quality of life [4]. Whilst there is increasing recognition that access to rehabilitative services is valued by people with chronic illness, regardless of their condition or prognosis [5], the optimal timing and composition of such interventions remains unclear [6]. A recent qualitative study conducted with palliative medicine specialists in Australia revealed attitudes towards palliative rehabilitation in advanced illness were divided, with some suggesting rehabilitation could do more harm than good by offering false hope of recovery [7]. To date advanced cancer rehabilitation guidance has largely been extrapolated from cancer survivor data or from evidence arising from interventions targeted at those receiving curative treatments [8]. Early multidisciplinary management, including rehabilitative strategies, may have a role in limiting or mitigating disability, if instigated at the earliest point at which these symptoms occur, but further research is warranted $[9,10,11,12]$. Active Palliative Rehabilitation in Lung Cancer (APRIL) was a 6 week individualised behaviour change programme combining physical activity, exercise and nutritional guidance, developed by a physiotherapist and dietitian alongside a multidisciplinary team of cancer and palliative care experts including nurses, medical practitioners, health psychologists, physiotherapists and dietitians. . It was designed to enhance quality of life, promote and maintain physical function and manage dietary symptoms associated with advanced inoperable NSCLC and its treatment in patients who were receiving systemic therapy with palliative intent. Based on Wade's definition of rehabilitation [13], palliative rehabilitation was defined as an educational, problemsolving process focused on activity limitations, aiming to optimise social participation and wellbeing, and so reduce stress on carer/family, within the context of a life-limiting progressive 
illness. Participants set personalised behaviour change goals which were revised and reassessed weekly as detailed in Table 1 using Transtheoretical Model of Behaviour Change [14].

Table 1 Active Palliative Rehabilitation in Lung Cancer (APRIL) Study Design

\begin{tabular}{|c|c|}
\hline Study design & Single cohort feasibility study \\
\hline $\begin{array}{l}\text { Start and end } \\
\text { date }\end{array}$ & February 2013 to February 2014 \\
\hline Venue & Regional Cancer Centre \\
\hline Stated aim & $\begin{array}{l}\text { To assess the composition, feasibility and acceptability of a palliative } \\
\text { rehabilitation programme for patients who are receiving systemic } \\
\text { (pharmaceutical agents used to combat cancer cells, wherever they are in } \\
\text { the body) therapy for advanced inoperable NSCLC }\end{array}$ \\
\hline $\begin{array}{l}\text { Study } \\
\text { intervention } \\
\text { details }\end{array}$ & $\begin{array}{l}\text { Individualised home based palliative rehabilitation programme combining a } \\
\text { walking programme and resistance activity at moderate intensity * and } \\
\text { dietary advice with individualised goal setting with weekly telephone support } \\
\text { based on Transtheroretical Model of Behaviour Change }{ }^{13}\end{array}$ \\
\hline $\begin{array}{l}\text { Inclusion } \\
\text { Criteria }\end{array}$ & $\begin{array}{l}\text { - Stage IIIb or IV NSCLC identified by the multidisciplinary team working } \\
\text { within the Northern Ireland Cancer Centre Lung Cancer Clinic } \\
\text { - Eastern Cooperative Oncology Group (ECOG) performance status } 0 \text { or } 1 \\
\text { - Recently commenced a palliative chemotherapy treatment (cycle } 1 \text { or } 2 \text { ) or } \\
\text { due to commence } \\
\text { - Physically able to undertake the interventions described within the APRIL } \\
\text { intervention }\end{array}$ \\
\hline $\begin{array}{l}\text { Exclusion } \\
\text { Criteria }\end{array}$ & $\begin{array}{l}\text { - Known co-morbidities which would severely impact upon physical } \\
\text { functioning or nutritional status such as poorly controlled diabetes, heart } \\
\text { failure, degenerative neuromuscular disease, inborn errors of metabolism or } \\
\text { renal insufficiency, mental health disorder or substance abuse } \\
\text { - Unable to understand and communicate in written and oral English and } \\
\text { over the phone sufficiently well enough to undertake the self-management } \\
\text { programme and weekly telephone review }\end{array}$ \\
\hline $\begin{array}{l}\text { Length of } \\
\text { intervention }\end{array}$ & $\begin{array}{l}\text { Six week active intervention with post outcome reassessment } 6 \text { weeks after } \\
\text { study completion and exit interview } 2 \text { weeks later }\end{array}$ \\
\hline $\begin{array}{l}\text { Outcome } \\
\text { measures }\end{array}$ & $\begin{array}{l}\text { Primary: Feasibility and acceptability } \\
\text { Secondary: Changes in quality of life, fatigue, functional status and nutritional } \\
\text { status pre, immediately post and } 6 \text { weeks post study, using validated } \\
\text { outcome measures }\end{array}$ \\
\hline
\end{tabular}

${ }^{*}$ guided by the ACSM's Guide to Exercise and Cancer Survivorship ${ }^{8}$ 
The purpose of the current study was to explore the experiences and perceptions of patients and healthcare professionals involved in the APRIL feasibility cohort study, hereafter referred to as APRIL, regarding the feasibility, acceptability, benefits and burdens of palliative rehabilitation as a component of advanced lung cancer management.

\section{METHODS}

\section{Design}

The study design was informed by previous cancer and advanced cancer rehabilitation research $[3,5,6,9,11]$. Drawing on the modelling process and outcomes component of the MRC Guidance for Developing and Evaluating complex interventions [15], data was collected on the multiple perspectives arising from patient and healthcare professionals involved in APRIL. Written consent was obtained and interviews were arranged at a time and place to suit the individual. Ethical and research governance approval for this study was obtained from, the Office for Research Ethics Committees Northern Ireland (ORECNI)(Reference number 12/NI/1042) and the research governance office of the clinical site. All participants provided informed written consent.

\section{Sample and setting}

APRIL was conducted at the Regional Care Centre in Northern Ireland, in adults with advanced NSCLC receiving systemic therapy with palliative intent. All patient $(n=8)$ and healthcare professionals $(n=9)$ involved in the APRIL study were invited to participate. Semi-structured interviews were conducted with eight patients with NSCLC who completed the APRIL study and six healthcare professionals involved in recruitment or outcome measurement. Table 2 presents demographic information on both sets of interview participants. 
Table 2 Characteristics of Interviewees

\begin{tabular}{|c|c|c|}
\hline \multicolumn{3}{|c|}{ Characteristics of APRIL Patient Participants $(n=8)$} \\
\hline Age & $\begin{array}{l}\text { Mean } \\
\text { Range }\end{array}$ & $\begin{array}{l}60 \text { years } \\
46 \text { to } 68 \text { years }\end{array}$ \\
\hline Gender & $\begin{array}{l}\text { - Female } \\
\text { - Male }\end{array}$ & $\begin{array}{l}3 \\
5\end{array}$ \\
\hline Cancer stage & $\begin{array}{l}-I I I B \\
-I V\end{array}$ & $\begin{array}{l}2 \\
6\end{array}$ \\
\hline Cancer type & $\begin{array}{l}\text { - Adenocarcinoma } \\
\text { - NSCLC of undetermined histology }\end{array}$ & $\begin{array}{l}6 \\
2\end{array}$ \\
\hline $\begin{array}{l}\text { Treatment received during } \\
\text { study }\end{array}$ & $\begin{array}{l}\text { - Pemetrexed Carboplatin } \\
\text { - Gemcitibine Carboplatin } \\
\text { - Erlotinib } \\
\text { - Gefitinib } \\
\text { - Gemcitibine Carboplatin } \\
\text { Radiotherapy }\end{array}$ & $\begin{array}{l}4 \\
1 \\
1 \\
1 \\
1\end{array}$ \\
\hline \multicolumn{2}{|c|}{$\begin{array}{l}\text { Treatment History } \\
\text { - First line palliative systemic therapy } \\
\text { - Second line palliative systemic therapy }\end{array}$} & $\begin{array}{l}7 \\
1\end{array}$ \\
\hline \multicolumn{3}{|c|}{ Characteristics of APRIL Healthcare Professional Participants $(n=6)$} \\
\hline Age range & $\begin{array}{l}30-39 \text { yrs } \\
40-49 \text { yrs } \\
50-65 \text { yrs }\end{array}$ & $\begin{array}{l}2 \\
3 \\
1\end{array}$ \\
\hline Gender & - Female & 6 \\
\hline Professional Background & $\begin{array}{l}\text { - Clinical trials nurse } \\
\text { - Clinical oncologist } \\
\text { - Medical oncologist }\end{array}$ & $\begin{array}{l}4 \\
1 \\
1\end{array}$ \\
\hline Mean years in Profession & $\begin{array}{l}\text { - Mean } \\
\text { - Range }\end{array}$ & $\begin{array}{l}17.5 \text { years } \\
11 \text { to } 34 \text { years }\end{array}$ \\
\hline Mean years in Specialist Cancer & $\begin{array}{l}\text { - Mean } \\
\text { - Range }\end{array}$ & $\begin{array}{l}10 \text { years } \\
8 \text { to } 13 \text { years }\end{array}$ \\
\hline
\end{tabular}




\section{Data collection}

Individual semi-structured interviews were conducted face-to-face, with the exception of one patient, who opted to be interviewed over the telephone. Interviews with patient participants were conducted by the primary researcher $(\mathrm{CP})$, who was a registered dietitian and $\mathrm{PhD}$ candidate with training in qualitative interviewing and included the questions outlined in Table 3.

\section{Table 3 Semi-structured Interview Questions}

\section{Semi-structured Interview Topic Guide for Patient Participants}

- What were your reasons for deciding to commence the active intervention programme?

- Of these reasons or thinking of any other reasons now, what had the most impact on your decision to engage in the physical activity and nutrition intervention?

- What were the most beneficial parts of the intervention?

- What were the least beneficial parts of the intervention?

- Would you recommend this programme to someone commencing chemotherapy for lung cancer?

- Can you suggest other interventions/programmes/activities that you feel would be of benefit for people with lung cancer?

- Is there anything else you would like to say?

\section{Semi-structured Interview Topic Guide for Healthcare Professional Participants}

- What were your thoughts on palliative rehabilitation before the study? Have these thoughts changed?

- What do you think your colleagues' thoughts were on palliative rehabilitation before the study? Do you feel these thoughts have changed?

- In what ways has the APRIL study influenced your practice, if any?

- What do you feel the reasons were that people decided to participate/ not to participate in this study?

- What, if anything, do you think might be the most beneficial/negative parts of participating in a palliative rehabilitation research study for the individual/ for their family?

- Is there anything that you would add/leave out? 
Interviews with healthcare professionals were conducted by a skilled independent qualitative interviewer using an interview schedule created by the research team to ensure that the healthcare professionals felt comfortable to voice thoughts, beliefs and opinions candidly. Interview questions included those outlined in table 3:

Both groups were also given opportunity to share any additional views and opinions that may not have been reflected in the questions posed.

\section{Data analysis}

All interviews were digitally recorded and transcribed verbatim, and field-notes were written immediately after each interview and during pertinent interactions with participants. Qualitative thematic analysis was used to explore the acceptability and experiences of APRIL using the six stages outlined by Newell and Burnard [16]. Data were independently coded by the lead author and verified by the multidisciplinary research team with complementary expertise in palliative care and rehabilitation, leading to the development of a set of sub-themes and overarching themes. The credibility of the themes was further tested by ensuring that these resonated with the data arising from field notes and study documentation.

Respondent validation exercises of data arising from sensitive topics may increase participant burden and cause distress, without necessarily enhancing rigour [16]. Additionally patients' participants were likely to have had disease related changes to health status in the intervening time between study participation and data analysis. For these reasons the researchers did not approach patients to review the study themes. Healthcare professionals were however invited to review and comment on the themes arising from their interviews with one healthcare professional taking up this opportunity and endorsing the findings.

\section{RESULTS}

Five themes were identified from patient interviews within an overarching theme of Living with and beyond an advanced cancer diagnosis (1) Challenges of living with incurable cancer (2) 
Personal and altruistic reasons for participating in rehabilitation (3) Applicability of palliative rehabilitation content (4) Barriers and facilitators to adherence (5) Positive impact on self and others. Three themes were identified from healthcare professionals, within an overarching theme of Palliative Rehabilitation: Exploring the concept (1) Pre-study mixed perceptions of palliative rehabilitation (2) Perceived benefits for patients and families (3) Lessons for future research.

Indicative quotations from the participants are presented against each subtheme below.

Participants have been anonymised and allocated a unique identifier.

\section{Patient themes}

Challenges of living with incurable cancer. Patients recognised that they had an illness from which there was no hope of recovery. This brought daily challenges in dealing with a limited prognosis and the uncertainty of how and when their condition might change.

“it's different when anybody says to you it's incurable...you just live from scan to scan" (patient 01)

However, despite recognising the incurable nature of their illness, patients did not preclude hopes for exceptional survivorship. This is evident in the quotation below, in which a participant talked about planning for future events and experiences.

“You're still breathing, get up and move, ye know? That's why I booked a holiday there for January... So I'm looking that bit forward, what, another six months down the line [laughs], ye know?" (patient 04).

Personal and Altruistic Reasons for Participating. Patients were asked why they had agree to participate in this study given the extent of their illness and incurable nature of the disease. The study was perceived to have important implications for helping others like themselves in 
determining the efficacy of rehabilitation within palliative care. It seemed that any quest for evidence to help others in their situation was welcomed.

"I think it is important... research to show whether it does or does not help, it's very important to find out." (patient 10)

In participating in APRIL, there was a realisation that it was an intervention, which was perceived as having minimal harm and disruption to daily lives. Study recruitment, baseline outcome measures and follow-up coincided as much as possible with scheduled hospital visits. This combined with the short duration of APRIL seemed to make participation acceptable to patients and were mentioned as key factors in the decision to participate.

"I was [at the hospital] all the time.... Whenever I read it all at the start, six weeks it's nothing... of your life, if it's going to prolong somebody else's" (patient 09)

An interesting theme that ran through discussions, was this desire to help others, several patients did not have expectations of personal gain when they volunteered, whilst for some there was an explicit hope for improvements in their own quality of life:

“...for my benefit and also if it helped, ye know helped others ... it was good for me, ye know? I'm always up for the challenge of doing something ... it's helped, I mean. I think it's got me motivated" (patient 05)

Applicability of Palliative Rehabilitation to Self. Participants were asked their views on the various aspects of the APRIL study which included the use of nutrition booklets, diary journaling and following an individually tailored programme of exercise. The guidance contained within the APRIL Physical Activity and Nutrition Guide booklet was deemed to be clearly written, with practical information that could be easily incorporated into their daily routines: 
"The plan was simplified and explained simply. As opposed to medical [terminology]. That you could get... you couldn't actually turn around and say "What does she mean by that?"... plain simple walking, talking, doing, eating" (patient 01)

Patients recognised that recording their physical activity and using a pedometer were motivators to reduce sedentary behaviour and to become more physically active. The daily noting down of physical activities gave patients a record of the goals they were working to and once attained, some were keen to progress further.

"it was the disciplined approach and getting up and doing the exercises every day and logging it. It was quite interesting to see how far with the wee pedometer on, how far I actually did walk.... Once you measure something .... It does become a bit of a challenge." (patient 10)

Barriers and Facilitators to Adherence. The structure and supportive framework, with collaborative individualised goal setting, was valued by participants. The weekly telephone support encouraged positive behaviour changes which were realistic and achievable, acknowledging the fluctuating impact of symptom burden.

"Very reassuring, you know what I mean. I knew I could have lifted the phone if I wasn't happy and you'd be there. Thank God I didn't have to do that. But I looked forward to [the weekly phone call]... It did [motivate me]" (patient 09)

Whilst all of the participants said that they would recommend the APRIL programme to others with advanced NSCLC receiving systemic therapy, they recognised that this type of intervention would not be suitable for all. APRIL was perceived to be of greatest value to those who were motivated but who needed reassurance and guidance on appropriate rehabilitation goals. 
"usually where lung cancer's associated, most people are old.... but for anyone being in that bracket, if they are having trouble walking... but then they come down and find they can do the six minute walk. That might tell them maybe they're not as bad as what they think" (patient 02)

Positive Impact on Self and Others. The positive psychosocial and physical benefits expressed by participants, included positivity for the future, increased capability to make positive behaviour changes and increased fitness. Physical activity and attention to dietary intake were perceived as beneficial for overall quality of life.

"food wise you've sorted me out ... and sleeping's better as well too. The exercise has helped as well... you've something interesting to do ... more so than.. lie on the settee or something." (patient 03)

Whilst the intervention was specifically targeted towards the individual with NSCLC, in keeping with the 'cues to action' contained within the TTM, participants were encouraged to seek and accept support from family and friends in attaining their personal physical activity and nutrition related goals.

"[my son] would say 'I hope you have that [pedometer] on'.... It was something different for my family too 'cause they were keeping an eye" (patient 01)

Whilst a diagnosis of advanced NSCLC was recognised to be challenging and life-changing, patient participants perceived that participation in the APRIL was not burdensome and brought physical and psychosocial benefits that many had not anticipated. APRIL motivated positive behaviour changes through simple individualised weekly goals determined by the patient themselves in consultation with a trained health professional guided by TTM. The approach was 
deemed to be of relevance to those wishing to have an active involvement in maintaining their own health and well-being during cancer treatment.

\section{Health care professional themes}

Pre-Study Mixed Perceptions of Palliative Rehabilitation. Many of the healthcare professionals involved in the recruitment, outcome measurement or review of patients on the APRIL study had limited knowledge and experience of palliative rehabilitation. Consequently, they had no expectation that the participants would gain personally from the study, but recognised the value of researching the topic.:

"when you're thinking about palliative care patients, I suppose rehabilitation isn't normally a word used. Palliative care from my perspective is more about supporting the patients and symptom control, and rehabilitation wasn't something that really I would have thought about an awful lot" (healthcare professional 06)

Some of the healthcare professionals presumed that the study would only be of interest to those who were already physically active, a factor which may have influenced decisions around participant suitability for the trial.

"I was also surprised how keen patients were to be enrolled in the study, if they knew about it, they were very keen and some actually that weren't able to take part because of practicalities ... were genuinely disappointed ... I was delighted with how pleased people were to take part and how well they did" (healthcare professional 03)

Failure to recognise any potential benefits of rehabilitation alongside advanced cancer treatment may have influenced decisions regarding patient suitability and the sharing of participant information with eligible patients. 
Perceived benefits for Patients and Families. Healthcare professionals perceived physical and psychosocial benefits in patients who adhered to the APRIL intervention. Participation in the study was welcomed as an additional type of palliative intervention, which had the possibility of motivating patients who may have otherwise have had low self-worth.

"another string to that bow of saying "We're going to treat you. This is going to be an active thing" ... as well as just the health benefits of feeling stronger, feeling more active, but psychologically, I think it really made them feel like "If I'm worth rehabilitating, I'm not just about to die just right now"." (healthcare professional 03)

The understanding of palliative rehabilitation changed markedly in those healthcare professionals who had no previous experience of similar interventions within advanced cancer populations.

"a lot of the patients as they're going through treatment struggle, they find the treatment very difficult, ... things get harder and I didn't see any patients that actually ... had [deteriorated during participation in APRIL], so maybe it maintained a level of fitness for them" (healthcare professional 06)

Positive impacts on family relationships were also commented upon. healthcare professionals felt that APRIL gave families and friends opportunities to help motivate and participate with patients in the rehabilitation process and provided validation that physical activity was not going to have a negative impact on disease progression.

"it helped [the family] not to ... wrap the patient up in cotton wool... if we're telling them get up, sit up, sit down, walk, then ... it's ok if they want to do that" (healthcare professional 03) 
And so it would seem that not only did APRIL not add to patient burden as some healthcare professionals had feared, but participation was felt to have positively impacted on physical and mental well-being and led to more supportive family relationships.

Lessons for Future Research. Healthcare professionals were keen to know when they would learn more about the findings from the study so that they could reflect on these to enhance future practice.

"It would be very interesting to see the full results [of APRIL]. The lead research nurse has been very positive about it, which I think is really encouraging..." (healthcare professional 05)

Whilst the study inclusion criteria had stipulated an Eastern Cooperative Oncology Group (ECOG) performance status [17] of zero or one, some healthcare professionals perceived that this type of study would benefit those with a lower performance status at diagnosis who had rehabilitation potential.

"It's that group who are performance status 2 ... because they're just either scared or the family won't let them do things... there's no doubt that we could have included some of those patients and it probably would have benefited a lot." (healthcare professional 04)

Interestingly, despite healthcare professionals being so positive about APRIL, there was a recognition that acquiring sufficient funding and resources to robustly research palliative rehabilitation was a limitation to definitive palliative rehabilitation trials in this area.

"to get anything new, there needs to be an evidence-base. ... and to prove something like this, you're going to need big, big studies..." (healthcare professional 03). 
Participants recognised the inherent difficulties in undertaking large scale evaluation studies of rehabilitation within palliative care and reaffirmed the importance of publishing small scale studies such as APRIL to continue to build the international knowledge base.

\section{DISCUSSION}

This study examined the concept of palliative rehabilitation and its feasibility and acceptability from the perspective of both patient participants and healthcare professionals involved in the recruitment and/or outcome measurement of patients with lung cancer to cancer clinical trials Findings related to the impact of living with advanced cancer, how palliative rehabilitation was interpreted (assessment), operationalised by participants (implementation) and its impact (outcomes) as depicted in Figure 1. It adds to the growing body of knowledge on palliative rehabilitation and its connection to physical and psychological well-being.

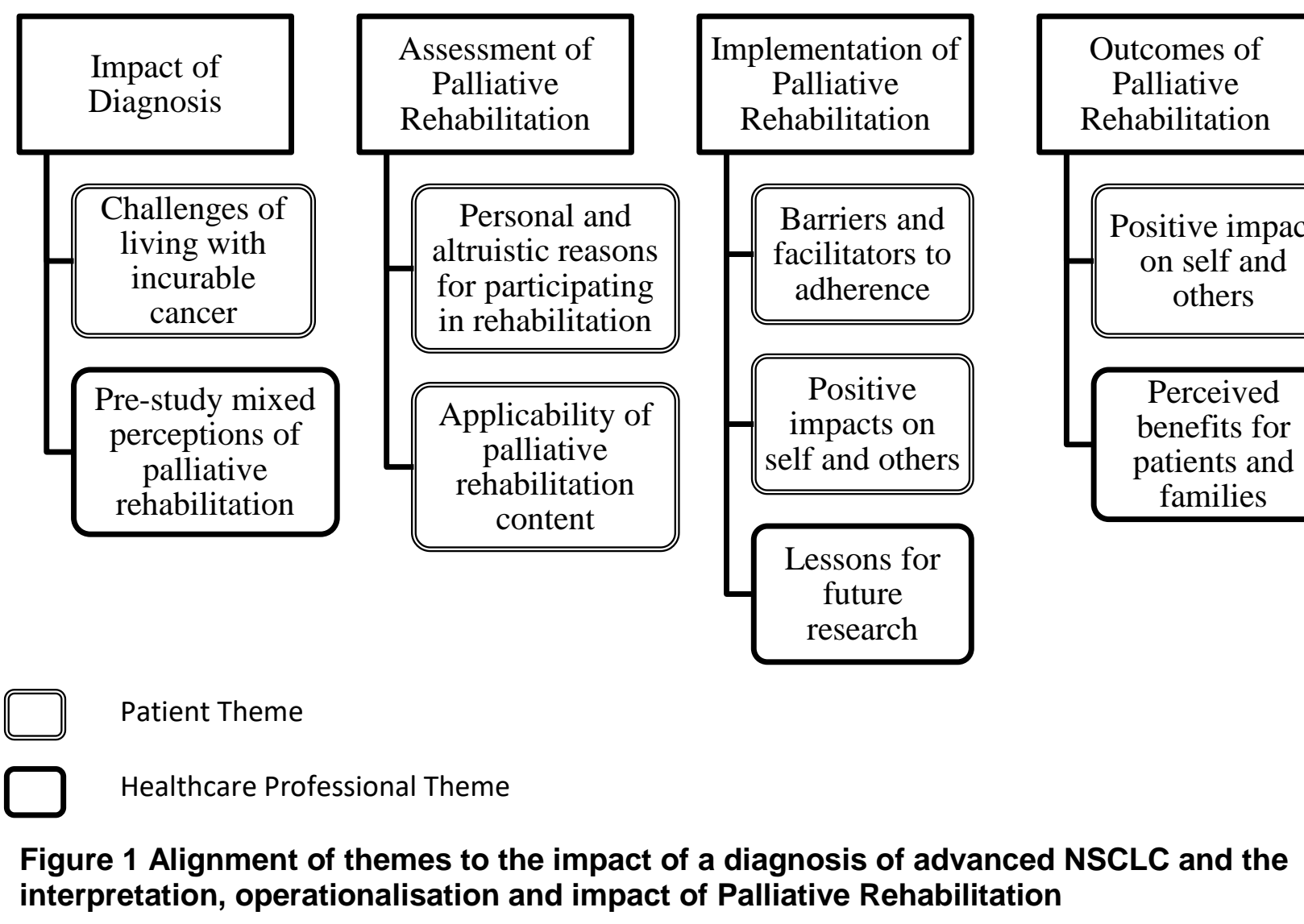


Findings revealed that both patient and healthcare professional participants perceived benefits of the individualised palliative rehabilitation guidance contained in APRIL. Patients were willing and able to engage in research despite having a poor prognosis. The majority of participants were motivated by the desire to improve the evidence base for future patients, rather than perceived opportunities for personal gain. These findings are similar to previous studies concerning recruitment to palliative care and palliative rehabilitation trials $[18,19]$.

\section{Limitations of the study}

This study demonstrates the acceptability and feasibility of one type of palliative rehabilitation intervention comprising nutrition and physical activity advice and included a relatively small number of participants. The mean age of the participants was lower than the typical age of patients receiving systemic therapy for NSCLC and all participants were white, with no representation from other ethnic groups. Additionally, some of the participants were already engaging in appropriate health behaviours and would have appeared to have had little to gain from engaging in the APRIL intervention. It is notable however that all participants perceived personal benefits from personalised rehabilitation guidance when reflecting on their experiences in the study. Participants were reasonably well with high baseline of physical functioning (ECOG $0-1)$ and were at the start of their cancer treatment. It remains to be seen if the findings have some transferability to the wider population of patients with advanced NSCLC receiving systemic therapy with palliative intent. Carer and family member perspectives were not assessed as this was beyond the scope of the project. The supportive network in which the patient lives has great potential to enhance functional well-being and perceptions of carers regarding the role of personalised rehabilitation interventions within palliative care is worthy of investigation. 


\section{Implications for Practice}

Initial concerns expressed by healthcare professionals about the appropriateness of palliative rehabilitation were tempered by witnessing positive impacts for patients and their families when engaging in the intervention. The majority view was that in future, study inclusion should be based on potential and desire for rehabilitation, rather than on subjective assessment of performance status. This is because physical deconditioning, at an early stage, may be amenable to improvement through appropriate support and guidance [20]. Optimal timing of the intervention continued to be questioned, with a recognition that services need to be responsive and flexible to individual circumstances including barriers to adherence, be they physical, psychological, or social, a finding which is consistent with the literature [21]. Earlier conversations regarding rehabilitation were however welcomed by participants. The findings of this study are contrary to the views held by many healthcare professionals that conversations regarding rehabilitation are best delayed until after cancer treatment is established or completed, so as not to overburden patients [7,21]. A willingness by patients to engage in dialogue about lifestyle choices is important as it is through such communications that clinicians may enable a focus on what matters to the patient, rather than solely discussing options for lifeextending treatment which may cause substantial physical and psychosocial burden $[22,23,24,25]$. This study also highlights the need for further research into how healthcare professionals' attitudes to rehabilitation alongside palliative cancer treatment affects service delivery and how rehabilitation might be more strategically aligned to oncological treatment plans as recommended in international policy and guidance [8,12,24,25]. 


\section{CONCLUSIONS}

Despite its limitations, the present study provided valuable insights regarding patient and healthcare professional attitudes to rehabilitation alongside palliative cancer treatment following exposure to an intervention developed by a physiotherapist and dietitian in conjunction with a wider multidisciplinary team of cancer and palliative care experts.

The individualised behaviour change programme which combined physical activity, exercise and nutritional guidance and weekly review was valued by participants and by healthcare professionals involved in the APRIL study. Participants stated they would recommend the intervention to those with NSCLC interested in maintaining their functional performance. Participants also discussed the utility of this rehabilitative approach to anyone facing functional decline as a consequence of advanced cancer.

Healthcare professionals who initially expressed negative attitudes towards palliative rehabilitation, displayed a mind-set change, adopting a more positive view of the impact that palliative rehabilitation might have in supporting patient well-being and quality of life. Personal experiences and perceptions acting as both barriers and facilitators to engaging in palliative rehabilitation were explored from both patient and healthcare professional perspectives, including perceived behavioural control and societal attitudes. Potential strategies for improving recruitment and retention of participants to this type of research study included increasing both patients and healthcare professionals' awareness of the role of rehabilitation in advanced cancer and widening study criteria to include all those who might benefit from targeted rehabilitation support, regardless of stage of treatment.

This study highlights the value of conducting palliative rehabilitation research within a clinical setting to understand the barriers and facilitators to behaviour change during advanced cancer treatment. As the prevalence of people living with advanced illness continues to rise, 
interventions that aim to improve function and quality of life need to be investigated systematically, so that people are able to maintain their personal goals towards quality of life.

\section{Authors' contributions}

All authors made substantial contributions to this research project: concept and design, data analysis and interpretation of data, and drafting and revising the manuscript critically for important intellectual content. All authors have read and approved the final version to be published and agree to be accountable for this work.

\section{Acknowledgements}

The authors would like to thank all the patients and healthcare professionals who participated for their time and interest in the study, the Northern Ireland Cancer Research Consumer Forum, Northern Ireland Cancer Trials Network and Dr Paula Scullin who acted as clinical site lead. All authors made substantial contributions to this research project: concept and design, data analysis and interpretation of data and drafting and revising the manuscript critically for important intellectual content. All authors have read and approved the final version to be published and agree to be accountable for this work.

\section{Funding}

The author(s) disclosed receipt of the following financial support for the research, authorship, and/or publication of this article: This study was funded through a doctoral fellowship by the All Ireland Institute of Hospice and Palliative Care (AIIHPC) and the Health and Social Care, Research and Development Division, Public Health Agency, Northern Ireland. The funders had no role in the study design, collection, analysis or interpretation of data, in writing the manuscript or in the decision to submit the manuscript for publication. 


\section{REFERENCES}

1. Blum TG, Rich A, Baldwin D, Beckett P, De Ruysscher D, Faivre-Finn C, et al. The European initiative for quality management in lung cancer care. Eur Respir J 2014; 43(5):1254-1277.

2. National Institute for Clinical Excellence Lung cancer: the diagnosis and treatment of lung cancer. Clinical Guideline 121. London: NICE, 2011

3. Rankin J, Robb K, Murtagh N, Cooper J, Lewis S. Rehabilitation in Cancer Care. WileyBlackwell; 2009.

4. WHO and WPCA. Global Atlas of Palliative Care at the End of Life. London: World Health Organization: Worldwide Palliative Care Alliance, 2014

5. Schleinich, MA, Warren, S, Nekolaichuk, C, Kaasa, T and Watanabe, S. Palliative care rehabilitation survey: A pilot study of patients' priorities for rehabilitation goals. Palliat Med, 2008; 22(7): 822-830.

6. Gracey, JH, Watson, M, Payne, C, Rankin, J and Dunwoody, L. Translation research: 'Back on Track', a multiprofessional rehabilitation service for cancer-related fatigue. BMJ Supportive \& Palliative Care 2014; pii: bmjspcare-2014-000692.

7. Runacres F, Gregory H, Ugalde A. 2016 'The horse has bolted I suspect': A qualitative study of clinicians' attitudes and perceptions regarding palliative rehabilitation. Palliat Med 31 (7), $642-650$

8. Irwin, ML. ACSM's Guide to Exercise and Cancer Survivorship. Illinois: Human Kinetics Publishers,2012

9. Payne, C, Wiffen, PJ and Martin, S. Interventions for fatigue and weight loss in adults with advanced progressive illness. CDSR, 2012. 1008427.

10. Eva, G and Wee, B. Rehabilitation in end-of-life management. Curr Opin Support Palliat Care, 2010; 4(3): 158-162. 
11. Payne, C, Larkin, PJ, Mcllfatrick, S, Dunwoody, L and Gracey, JH. Exercise and Nutritional Interventions in Advanced Lung Cancer: A Systematic Review. Curr Oncol, 2013; 20: e321e337.

12. Nadler, M., Bainbridge, D., Tomasone, J., Cheifetz, O., Juergens, R.A. and Sussman, J., 2017. Oncology care provider perspectives on exercise promotion in people with cancer: an examination of knowledge, practices, barriers, and facilitators. Support Care Cancer, 25(7), pp.2297-2304.

13. Wade, DT. Describing rehabilitation interventions. Clin Rehabil, 2005; 19(8): 811-818.

14. Prochaska, JO and Velicer, WF. The transtheoretical model of health behavior change. Am J Health Promot, 1997; 12(1): 38-48.

15. Craig, P, Dieppe, P, Macintyre, S, Michie, S, Nazareth, I and Petticrew, M. Developing and Evaluating Complex Interventions: new guidance. London: Medical Research Council, 2008

16. Newell, R. and Burnard, P. Research for Evidence-Based Practice in Healthcare. Oxford: John Wiley \& Sons. 2011

17. Oken, MM, Creech, RH, Tormey, DC, Horton, J, Davis, TE, McFadden, ET and Carbone, PP. Toxicity and response criteria of the Eastern Cooperative Oncology Group Am J Clin Oncol, 1982; 5(6): 649-656.

18. Paltiel, H, Solvoll, E, Loge, JH, Kaasa, S and Oldervoll, L. "The healthy me appears": Palliative cancer patients' experiences of participation in a physical group exercise program. Palliat Support Care, 2009; 7(04): 459-467

19. Perkins, $P$, Barclay, $S$ and Booth, $S$ What are patients' priorities for palliative care research? Focus group study. Palliat Med, 2007; 21(3): 219-225.

20. Fearon, K, Strasser, F, Anker, SD, Bosaeus, I, Bruera, E, Fainsinger, RL, Jatoi, A, Loprinzi, C, MacDonald, N, Mantovani, G, Davis, M, Muscaritoli, M, Ottery, F, Radbruch, L, Ravasco, P, Walsh, D, Wilcock, A, Kaasa, S and Baracos, VE. Definition and classification of cancer cachexia: an international consensus. Lancet Oncol, 2011; 12(5): 489-495. 
21. Wagland R, Ellis J, Bailey CD, Haines J, Caress A, Williams ML, Lorigan P, Smith J, Tishelman C \& Booton R Considerations in developing and delivering a nonpharmacological intervention for symptom management in lung cancer: the views of health care professionals. Support Care Cancer, 2012; 20(10): 2565-2574.

22. Irwin, KE, Greer, JA, Khatib, J, Temel, JS. and Pirl, WF. Early palliative care and metastatic non-small cell lung cancer: potential mechanisms of prolonged survival. Chronic Respir Dis, 2013; 10(1): 35-47.

23. Feldstain A, MacDonald N, Bhargava R, Chasen M. Reported distress in patients living with advanced cancer: changes pre-post interdisciplinary palliative rehabilitation. Support Care Cancer 2017; 10.1007/s00520-017-3728-2.

24. Chasen M, Bhargava R, MacDonald N. Rehabilitation for patients with advanced cancer. CMAJ. 2014 Oct 7;186(14):1071-5.

25. Barawid E, Covarrubias N, Tribuzio B, Liao S. The benefits of rehabilitation for palliative care patients. Am J Hosp Pall Med. 2015 Feb;32(1):34-43. 